\title{
Enhancing biodiversity of agrocenosis by planting selected flowering plant species
}

\section{Wzbogacanie różnorodności biologicznej agrocenoz poprzez wysiewanie wybranych gatunków roślin kwitnących}

\author{
Zbigniew T. Dąbrowski ${ }^{1}$, Michał Hurej ${ }^{2}$, Janusz Nowacki ${ }^{3}$, Witold Łykowski ${ }^{4}$, Monika Borkowska ${ }^{4}$
}

\begin{abstract}
Summary
The changes in agriculture in the majority of Western European countries since 1950, which were supposed to lead into more effective production through enlarging field sizes and increased mechanization that required removal of field margins, hedges, ponds and other uncultivated areas have resulted in the reduction of biodiversity. The paper aims to show that it is feasible and practical to balance biodiversity, conservation and protection of resources with agriculture production on the farm. Farmers are being encouraged to provide more flowering habitats to support pest natural enemies and pollinators in the agro-ecosystems. Some examples of research projects carried out by participants of the International Organisation of Biological Control working group on "Landscape management for functional biodiversity" on the positive effects of various flowering plant species and their mixtures on beneficial organisms are cited in this publication. Their recommendations shall be adapted to the Polish conditions during the implementation of the Directive 2009/128/EC regarding the Integrated Pest Management recommendation on utilization of ecological infrastructures inside and outside production sites to protect and enhance beneficial organisms (after Annex III).
\end{abstract}

Key words: biodiversity, ecological infrastructure, flowering plants, natural enemies

\section{Streszczenie}

Zmiany wprowadzane od roku 1950 w rolnictwie w wielu krajach Europy Zachodniej, w celu intensyfikacji produkcji poprzez powiększanie wielkości pól oraz wprowadzenie mechanizacji na szeroką skalę spowodowały wyeliminowanie miedz, zarośli i zbiorników śródpolnych, jak i nieużytków rolnych, co doprowadziło do znacznego ograniczenia różnorodności biologicznej w agrocenozach. Praca ta ma na celu wskazanie, że jest możliwe w praktyce zapewnienie równowagi pomiędzy bioróżnorodnością, ochroną i zachowaniem zasobów naturalnych a produkcją rolniczą w gospodarstwie. Rolnicy są zachęcani do tworzenia liczniejszych habitatów z kwitnącymi roślinami w celu utrzymania populacji wrogów naturalnych szkodników i owadów zapylających w agrocenozach. W pracy podano wybrane wyniki badań, szczególnie uczestników grupy roboczej „Zarządzanie krajobrazem dla bioróżnorodności funkcjonalnej” Międzynarodowej Organizacji Walki Biologicznej, nad pozytywną rolą różnych gatunków kwitnących roślin lub ich mieszanek na pożyteczne gatunki stawonogów. Zalecenia autorów powinny zostać zaadoptowane do warunków Polski w czasie wdrażania Dyrektywy 2009/128/WE dotyczącej zasad integrowanej ochrony roślin (IPM - integrated pest management), szczególnie wykorzystania ekologicznych struktur w miejscu produkcji i poza nią w zapobieganiu występowaniu organizmów szkodliwych (za Aneksem III).

Słowa kluczowe: bioróżnorodność, infrastruktura ekologiczna, rośliny kwitnące, wrogowie naturalni

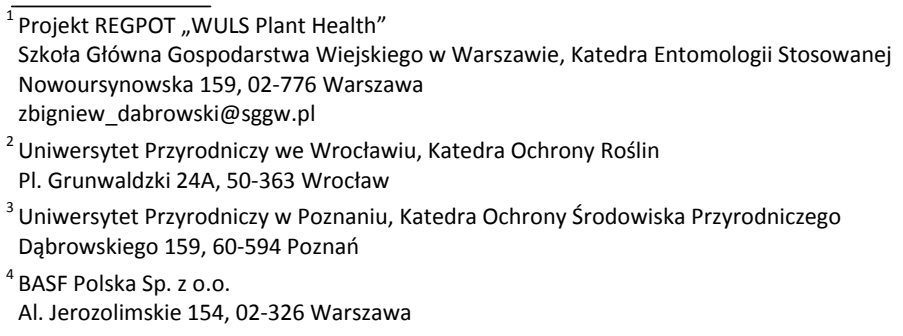




\section{Wstęp / Introduction}

Konieczność zapewnienia rosnącego zapotrzebowania na żywność po drugiej wojnie światowej spowodowała gwałtowne zmiany w produkcji rolniczej w wielu krajach w Europie. Intensyfikacja produkcji była możliwa dzięki wprowadzeniu powszechnej mechanizacji rolnictwa, powiększeniu wielkości pól, wprowadzeniu do uprawy nowych odmian, stosowaniu herbicydów i chemicznych środków ochrony roślin (ś.o.r.). Aby optymalnie wykorzystać sprzęt mechaniczny eliminowano miedze, żywopłoty śródpolne i ograniczano naturalne pastwiska. Wprowadzone zmiany w znacznym stopniu wpłynęły na ograniczenie różnorodności biologicznej występującej w środowiskach agroekosystemów (Ryszkowski 2002; Nowacki 2007). Stąd od ponad 20 lat pojawiły się opracowania wskazujące, że w takich warunkach patogeny i szkodniki znajdują niewyczerpalne zasoby pokarmowe i przy braku występowania naturalnych czynników antagonistycznych, dochodzi częściej do epidemii chorób i masowych pojawów szkodników (Dąbrowski 2010).

Problemy te dostrzegła również Międzynarodowa Organizacja Walki Biologicznej (International Organization of Biological Control - IOBC) powołując w 2003 r. grupe roboczą: "Landscape management for functional biodiversity" (,Zagospodarowanie krajobrazu dla funkcjonalnej różnorodności biologicznej”) (Rossing i wsp. 2003). Jednocześnie Komisja Europejska w swojej Dyrektywie Parlamentu Europejskiego i Rady Europy 2009/128/WE w załączniku III dotyczącym ogólnych zasad integrowanej ochrony roślin zaleca ochronę i stwarzanie warunków dla występowania ważnych organizmów pożytecznych, np. poprzez stosowanie odpowiednich metod ochrony roślin lub wykorzystywanie ekologicznych struktur w miejscu produkcji i poza nią (European Parliament 2009). Obecnie prowadzone dyskusje w ramach Komisji Europejskiej ds. Środowiska (European Commission Directorate-General Environment) i krajach członkowskich dotyczą wielkości powierzchni przeznaczonej na infrastrukturę ekologiczną gospodarstw i postulowanych przez organizacje producentów rolnych wielu krajów rekompensat dla rolników za prowadzenie działań pro-środowiskowych (Anonymus 2010).

\section{Zalecane rodzaje infrastruktury ekologicznej agrocenoz / Recomended types of ecological infrastructures in agrocenosis}

$\mathrm{Na}$ infrastrukturę ekologiczną gospodarstw składają się: elementy liniowe (linearne) i nieliniowe. Do liniowych elementów zalicza się istniejące lub planowane: miedze z kwitnącymi roślinami, żywopłoty lub pasy zarośli śródpolnych, rowy, kamienne mury oporowe. Ważnym jest, aby te elementy zapewniały ciągłość w czasie i przestrzeni dla wzbogacenia różnorodności fauny i utrzymania zróżnicowanego krajobrazu.

Wykorzystuje się następujące struktury:

- Miedze lub pasy brzeżne pól pokryte trawami i/lub kwitnącą roślinnością. Badania nad optymalnym składem gatunkowym mieszanki roślin kwitnących dla tych celów podjęto w 2008 r. w projekcie HortLink "Perennial field margin with combined agronomic and ecological benefits for vegetable rotation scheme" W ramach programu "Linking Environment and Farming" w Wielkiej Brytanii (George i wsp. 2010). Pasy naturalnej roślinności, wysianych traw i roślin kwitnących jako jeden $\mathrm{z}$ instrumentów wspierania działań rolno-środowiskowych założyli rolnicy austriaccy na obszarze 23968 ha, w ramach umowy o przekształceniu $2 \%$ gruntów na siedliska dla fauny pożytecznej (Anonymus 2010).

- Korytarze ekologiczne: pasy krzewów śródpolnych, drogi polne, murki oporowe, kanały i strumienie. W ramach projektu BIODIVINE, europejskiego programu LIFE+ opracowano zalecenia optymalnego rozmieszczenia nowych nasadzeń żywopłotów jako korytarzy ekologicznych dla regionu Saumur-Champigny (van Helden i wsp. 2012). Na pagórkowatych terenach Dolnej Austrii podjęto próby naprawy i konserwacji murków oporowych. Stwierdzono, że rozwijająca się na nich i w ich otoczeniu roślinność jest siedliskiem 550 ekotypów i gatunków roślin, a wśród nich wielu śródziemnomorskich gatunków chronionych (Anonymus 2010).

- Elementy izolowane (fragmentaryczne), ciekawie określane jako "stepping stones" - kamienie w błocie, kałuże do przejścia. Reprezentują one habitaty mniejsze, o dużej koncentracji różnych elementów, w których okresowo mogą się rozwijać populacje zwierząt. Zalicza się do nich: zadrzewienia śródpolne, kępy zarośli, zbocza kamienne z roślinnością i stawy. Na terenach spółdzielni Coop de France (Francja) zrzeszającej rolników uprawiających lucernę na suchą paszę, przy aprobacie suszarni, zdecydowano się na zmianę terminów koszenia lucerny, zostawiając część pól do czasu kwitnienia tej rośliny. Te części pól stały się ostoją dla populacji motyli, pszczół i innych pożytecznych stawonogów oraz ptaków i nietoperzy. Projekt ten jest wynikiem współpracy 45 rolników, pszczelarzy, organizacji środowiskowych i zarządu zakładu suszenia pasz (Anonymus 2010).

- Duże i trwałe biocenozy (habitaty), jak: lasy, sady, naturalne łąki (Boller i wsp. 2004).

Wielokrotnie udowodniono, że efektywność różnych elementów infrastruktury ekologicznej położonych na terenie gospodarstwa, wzbogacających biologiczną różnorodność, zależy od ich wartości ekologicznych, rozmieszczenia $i$ powiązań $z$ innymi elementami infrastruktury ekologicznej położonych poza gospodarstwem. Sama w sobie różnorodność biologiczna agrocenoz nie zapewnia jej funkcjonalnego znaczenia dla utrzymania równowagi biologicznej $\mathrm{w}$ uprawie (van Emden i Dąbrowski 1994).

Zgodnie z zaleceniami grupy ekspertów Międzynarodowej Organizacji Walki Biologicznej (IOBC - International Organisation of Biological Control) dotyczących utrzymania różnorodności biologicznej (bioróżnorodności) infrastruktura ekologiczna powinna zajmować przynajmniej 5\% (optymalnie 15\%) powierzchni gospodarstwa, nie wliczając $\mathrm{w}$ to lasów. W rejonach o dużej liczbie małych gospodarstw obowiązek ten nie powinien obo- 
wiązywać, ale nakłada to na lokalne samorządy zapewnienie istnienia 5\% obszaru danego rejonu (gminy) jako terenów kompensacji ekologicznej. Cytowane wyżej zalecenie IOBC dotyczące pierwszeństwa wykorzystania mechanizmów naturalnej regulacji procesów biologicznych wskazuje również na konieczność stworzenia warunków sprzyjających występowaniu drapieżców i parazytoidów w agrocenozach poprzez odpowiednie kształtowanie tzw. infrastruktury ekologicznej w ramach pól i ich otoczeniu. Obecnie prowadzone dyskusje na forum Komisji Europejskiej mają na celu określenie wielkości areału przeznaczonego na wybrane elementy infrastruktury ekologicznej w każdym gospodarstwie w krajach Unii Europejskiej.

\section{Aktualny stan badań nad znaczeniem infrastruktury ekologicznej dla funkcjonalnej bioróżnorodności / Actual state of research on the importance of ecological infrastructures on functional biodiversity}

Badania prowadzone w Unii Europejskiej w okresie ostatnich siedmiu lat nad wzbogaceniem funkcjonalnej różnorodności ekologicznej dotyczyły:

- atrakcyjności poszczególnych gatunków roślin kwitnących jako pożytku dla dzikich gatunków pszczołowatych, parazytoidów i drapieżców;

- optymalnego składu gatunkowego roślinności miedz i otoczenia pól uprawnych;

- optymalnego planowania korytarzy ekologicznych w agrocenozach;

- optymalnego rozmieszczenia elementów fragmentarycznych w badanych regionach.

Obecnie prowadzone dyskusje i konsultacje międzynarodowe w ramach Komisji Europejskiej dotyczące udziału infrastruktury ekologicznej w gospodarstwie zmierzają do określenia około $7 \%$ powierzchni gospodarstwa objętego tego typu programem. Jednak należy zaznaczyć, że zarówno w Polsce, jak i międzynarodowych programach okołośrodowiskowych wyraźnie stwierdza się, że wprowadzenie takich zasad w Europie powinno zawierać warunki rekompensaty za działania rolników na rzecz zachowania bioróżnorodności agrocenoz i walorów środowiska (Anonymus 2010).

\section{Ocena wartości poszczególnych gatunków roślin dla bioróżnorodności funkcjonalnej / Estimation of the value of individual plant species for functional biodiverity}

Kwitnące rośliny jednoroczne, dwuletnie i trwałe byliny zaspokajają różne potrzeby środowiskowe wrogów naturalnych szkodników poprzez:

- dostarczanie pokarmu uzupełniającego koniecznego do uzyskania dojrzałości płciowej przez osobniki dorosłe parazytoidów: nektar, pyłek, spadź;

- źródło pokarmu dla owadów zapylających, szczególnie w okresach, gdy rośliny uprawne nie kwitną;
- zapewnienie dodatkowych źródeł pokarmu dla drapieżców i alternatywnych żywicieli parazytoidów, szczególnie w okresie braku szkodników na roślinach uprawnych. Rozwój wrogów naturalnych na roślinności ostoi ekologicznych jest szczególnie ważny wiosną w okresie, gdy szkodniki zaczynają dopiero zasiedlać uprawy;

- zmianę mikroklimatu zapewniającego korzystne warunki dla wrogów naturalnych oraz zapewnienie miejsca przeżycia i schronienia, np. w czasie zabiegów agrotechnicznych.

W krajach południowej Europy drapieżne pluskwiaki z rodzaju Macrolophus Fieber, Dicyphus Fieber i Nesidiocoris (Reuter) $\mathrm{z}$ rodziny tasznikowatych (Miridae) są ważnymi wrogami naturalnymi mszyc i mączlików w uprawach warzyw. Występują one licznie na takich gatunkach chwastów, jak: Dittrichia viscosa (Asteraceae) i psianka czarna Solanum nigrum L. (Solanaceae) rosnących w pobliżu upraw pomidorów. Wykazano ich korzystne oddziaływanie na zmniejszenie populacji szkodników na pomidorach rosnących na brzeżnych rzędach (Perdikis i wsp. 2007).

W Hiszpanii potwierdzono aktywne przemieszczanie się drapieżnych plukwiaków $\mathrm{z}$ rodziny tasznikowatych pomiędzy ekosystemami w środowisku. Pluskwiak Macrolophus caliginosus Wagner zasiedlając różne rośliny dziko rosnące w znacznym stopniu ogranicza populacje mączlików atakujących uprawy polowe pomidorów. W okresie od kwietnia do czerwca licznie występuje on na naturalnych stanowiskach Inula viscosa, następnie przenosi się na rośliny uprawne. W okresie zimy tworzy on znaczne populacje na roślinach gatunku Cistus albidus L., które wytwarzają nowe pędy jesienią. Może on zimować zarówno na pozostałościach po zbiorach pomidorów i ogórków, jak i na $I$. viscosa i krzewach zimozielonych Cistus spp. (Alomar i Albajes 2003).

Rośliny kwitnące $\mathrm{z}$ jednej strony mogą być wykorzystywane jako rośliny pułapkowe dla szkodników, a z drugiej jako źródło pokarmu dla ich wrogów naturalnych (Badenes-Pérez i Márquez 2012). Gorczycznik pospolity (Barbarea vulgaris R. Br.) (Brassicaceae) okazał się rośliną pułapkową dla tantnisia krzyżowiaczka (Plutella maculipennis Curt.) i jednocześnie dobrym źródłem nektaru dla trzech gatunków parazytoidów: Cotesia plutellae Kurdj. (Braconidae); Diodromus collaris Grav. (Ichneumonidae); Diadegma insulare Cres. (Ichneumonidae) i dorosłych Syrphidae: Sphaerophopra scripta L. i Eupeodes corollae F.

\section{Wykorzystanie mieszanek roślin kwitnących dla wzbogacenia funkcjonalnej różnorodności biologicznej agrocenoz / Use of the flowering plant species to enhance functional biodiversity in agroecosystems}

Istotny wpływ pasów z wysianymi mieszankami roślin kwitnących na populację gąsienic motyli, szkodników kapusty wykazano $\mathrm{w}$ badaniach przeprowadzonych w dwóch regionach w Szwajcarii. W jednym doświadczeniu analizowano wpływ trzyletniego pasa obsianego 
27 gatunkami dzikich roślin, w drugim jednoroczny pas obsiany 36 gatunkami. Omawiane pasy traktowano jako sztuczne miedze, które miały szerokość $3 \mathrm{~m}$ i długość 140 i 195 m (Pfiffner i wsp. 2003). Kontrolę stanowiły uprawy kapusty, do których nie przylegały miedze z kwitnącymi roślinami. $\mathrm{Na}$ kwitnących roślinach odłowiono 1025 gatunków pasożytniczych błonkówek z 17 rodzin. Okazało się, że spasożytowanie gąsienic bielinka rzepnika i piętnówki kapustnicy było wyższe na poletkach kapusty czerwonej przylegających do pasów dzikich roślin kwitnących, chociaż nie wykazano prostej zależności pomiędzy intensywnością spasożytowania piętnówki kapustnicy a odległością od kwitnących roślin.

W badaniach przeprowadzonych w Polsce wykazano, że sztuczne miedze obsiane mieszanką złożoną z gorczycy białej (Sinapis alba L.), facelii błękitnej (Phacelia tanacetifolia Benth.) oraz kolendry siewnej (Coriandrum sativum L.) przywabiają liczne owady drapieżne, szczególnie Coccinellidae oraz Syrphidae (Hurej i wsp. 1998; Twardowski 2002; Twardowski i wsp. 2006). Spośród Syrphidae najliczniejszymi były gatunki, których larwy odżywiają się głównie mszycami. Omawiane pasy kwitnących roślin były też bardzo atrakcyjne dla owadów zapylających, takich jak pszczoła miodna oraz trzmiele. W badaniach cytowanych autorów, pozytywną reakcję na wysiew mieszanki odnotowano również w przypadku stawonogów epigeicznych, tj. chrząszczy z rodziny biegaczowatych (Carabidae), kusakowatych (Staphylinidae) i pajęczaków (Arachnida).

Dla osobników dorosłych wielu gatunków parazytoidów, cukry są ważnym pokarmem jako główne źródło energii, zwiększając ich przeżywalność, płodność i mobilność. Nektar, spadź i pyłek są najczęściej wykorzystanym źródłem ich pokarmu w warunkach polowych (Jervis i Kidd 1986). Pasy długo kwitnących roślin spełniają te wymagania. Liczne badania prowadzone według metodyki "on-farm research" wskazują, że miedze z kwitnącymi dzikimi gatunkami roślin zwiększają różnorodność i liczebność pasożytniczych błonkówek, a tym samym mogą znacznie zwiększać spasożytowanie jaj i gąsienic motyli. Jednak nie wszystkie kwitnące rośliny w równym stopniu zwiększają biologiczną aktywność parazytoidów. Poza tym, osobniki dorosłe niektórych szkodników też pobierają pokarm z kwiatów roślin rosnących na miedzach, czy chwastów wśród upraw.

Zespół dr. Wäckers'a wykorzystując wysoko rozdzielczą chromatografię cieczową (HPLC - high-performance liquid chromatography) analizował jakość pokarmu pobieranego przez osobniki dorosłe parazytoidów Cotesia glomerata (L.) i Microplitis mediator (Hal.) oraz motyli bielinka kapustnika Pieris brassicae (L.) i piętnówki kapustnicy Mamestra brasscae (L.) z kwiatów lub spadzi wydzielanej przez mszyce na kapuście brukselce (Wäckers i wsp. 2006). Na obrzeżach poletek z brukselką wysiano 11 jednorocznych gatunków roślin kwitnących. Okazało się, że np. pokarm zebrany z kwiatów (a) chabra łąkowego (Centaurea jaces L.) jest szczególnie korzystny dla bielinka rzepnika (Pieris rapae L.); (b) lobularii nadmorskiej [Lobularia maritima (L.) Desv.] i kopru ogrodowego dla tantnisia krzyżwiaczka Plutella xylostella (L.); (c) kopru ogrodowego (Anethum graveolens L.) dla parazytoidów a (d) gryki zwyczajnej (Fagopyrum esculentum Moench) dla bielinków i parazytoidów. Parazytoid Diadegma semiclausum Hellén najliczniej nalatywał na uprawę brukselki, a badania laboratoryjne i polowe wykazały, że kwitnące rośliny gryki zwyczajnej i kopru ogrodowego miały istotny wpływ na płodność tego gatunku (Winkler i wsp. 2006).

Oceniając biologiczną wartość mieszanek roślin kwitnących wysiewanych na obrzeżach pól przyjęto takie wskaźniki, jak: wzrost i adaptacja do warunków miedzy (plant establishment - zasiedlenie) i okres kwitnienia poszczególnych gatunków.

Barbir i wsp. (2012) w badaniach polowych prowadzonych w Hiszpanii ocenili wartość różnych gatunków roślin dla wybranych grup owadów pożytecznych:

(A) Kolejność atrakcyjności dla pszczołowatych:

(a) najbardziej atrakcyjne: Borago officinalis L. ogórecznik lekarski i Phacelia tanacetifolia Benth. - facelia wrotyczolistna (błękitna);

(b) nieco niższa atrakcyjność: Diplotaxis muralis (L.) - dwurząd murowy; Echium plantagineum L. żmijowiec babkowy i Mieszanka M2 składająca się z 6 gatunków roślin;

(c) znacznie niższa atrakcyjność: Calendula arvensis L. - nagietek polny; Centaurea cyanus L. - chaber bławatek i Coriandrum sativum L. - kolendra siewna;

(d) znikoma atrakcyjność: Tagetes patula L. aksamitka rozpierzchła i Lobularia maritima L. lobularia nadmorska (smagliczka).

(B) Kolejność atrakcyjności dla bzygowatych:

(a) wysoka atrakcyjność: Calendula arvensis L. nagietek polny i Diplotaxis muralis (L.) dwurząd murowy;

(b) nieco niższa atrakcyjność: Coriandrum sativum L. - kolendra siewna; Lobularia maritima L. - lobularia nadmorska (smagliczka) i Mieszanka M1 składająca się z 6 gatunków roślin;

(c) znacznie niższa atrakcyjność: Borago officinalis L. - ogórecznik lekarski; C. cyanus L. - chaber bławatek; P. tanacetifolia Benth. - facelia wrotyczolistna (błękitna) i Echium plantagineum L. żmijowiec babkowy (Barbir i wsp. (2012).

Większość obserwacji nad przydatnością poszczególnych gatunków roślin i ich mieszanek dla organizmów pożytecznych pochodzi z innych regionów Europy, dlatego istnieje potrzeba wstępnej oceny przydatności tych gatunków dla warunków Polski. W pracach zespołu dr. Wäckers'a (Wielka Brytania) ocena obejmowała następujące parametry:

(a) wschody, wzrost młodych roślin i pokrycie powierzchni określane w 3-4 powtórzeniach wykonywanych w miesięcznych odstępach od wiosny do jesieni;

(b) terminy pełnego kwitnienia pojedynczych roślin poszczególnych gatunków, przynajmniej na 3-4 miedzach;

(c) określenie zasiedlenia roślin w skali $0-5$ przez mszyce jako rezerwuar ("banker plants") alternatywnych żywicieli dla parazytoidów i ofiar dla 
larw bzygowatych i złooków (George i wsp. 2012).

Cytowane powyższe badania były prowadzone w ramach programu HortLINK jako partnerskiego programu badawczego przemysłu i nauki (www.ecostac.uk).

\section{Wstępne obserwacje nad atrakcyjnością wybranych gatunków roślin kwitnących wysiewanych w mieszance w Polsce / Preliminary observations on attractiveness of flowering plant species planted in a mixture under Polish conditions}

Obserwacje polowe nad oddziaływaniem mieszanki kwitnących roślin na pożyteczne stawonogi zainicjowano na polach uprawnych na terenie: (a) Centrum Kompetencyjnego BASF Polska w Pagowie (województwo opolskie), (b) Centrum Kompetencyjnego BASF Polska w Jarosławcu koło Środy Wielkopolskiej i Rolniczego Zakładu Doświadczalnego Szkoły Głównej Gospodarstwa Wiejskiego w Oborach koło Warszawy w 2012 r. Celem badań jest obserwacja zmian w cyklu wieloletnim składu gatunkowego organizmów pożytecznych występujących na polach (około 1 ha) obsianych mieszanką kwitnących roślin oraz wpływu mieszanki na organizmy pożyteczne występujące na polach znajdujących się w jej sąsiedztwie. Analiza wzrostu i pokrycia powierzchni pola przez poszczególne gatunki roślin wskazała na dominujący udział słonecznika, zagłuszający wzrost innych roślin w mieszance. Lokalne warunki klimatyczne, jakość gleby i konsekwencje wpływu poprzednich upraw decydowały o wzroście poszczególnych gatunków w mieszance w okresie wegetacyjnym.

Dodatkowe szczegółowe obserwacje nad preferencja różnych gatunków roślin wchodzących w skład mieszanki przygotowanej przez firmę nasienną SaarenZeller (Niemcy) przez różne grupy stawonogów prowadzono na Polu Doświadczalnym w Ursynowie. Mieszanka ta została przygotowana w ramach projektu „Zrównoważone rolnictwo i bioróżnorodność w harmonii” (BASF 2011).

Wyniki wykazały, że:

(a) pszczoła miodna i trzmiele, niezależnie od metodyki prowadzonych obserwacji (metoda transektów lub bezpośrednich obserwacji na kwiatach) najliczniej występowała na facelii błekitnej;

(b) W następnej kolejności najchętniej odwiedzanymi przez pszczołę miodną były: złocień polny, słonecznik i nagietek polny;

(c) dzikie pszczoły najliczniej odwiedzały rośliny złocienia polnego;

(d) dorosłe muchówki bzygowatych około 4-, 5-krotnie częściej wybierały kwiaty złocienia polnego w porównaniu do gryki zwyczajnej. Znacznie mniej bzygowatych osiadało na kwiatach nagietka lekarskiego i facelii błękitnej w stosunku do gryki zwyczajnej. W okresie sierpnia i września pojedyncze muchy wybierały też kwiaty kopru zwyczajnego i kolendry siewnej.

\section{Literatura / References}

Alomar O., Albajes R. 2003. Habitat management for conservation of the native predator Macrolophus caliginosus. IOBC/WPRS Bull. 26 (4): $7-12$

Anonymous. 2010. Bioróżnorodność w rolnictwie. Copa*Cogena. European farmers. European agri-cooperatives. Bruxelles, 28 pp.

Badenes-Pérez F.R., Márquez B.P. 2012. Effect of flowering trap crop on insect pests and their natural enemies. IOBC/WPRS Bull. 75: 21-23.

Barbir J., Martin J.M., Campos D., Quintanilla C.F., Badenez-Pérez F.R., Dorado J. 2012. Attractiveness of flowers of different plant species to bees (Hymenoptera: Apoidea) and hoverflies (Diptera: Syrphidae) of central Spain. IOBC/WPRS Bull. 75: 25-28.

BASF. 2011. Bioróżnorodność a rolnictwo. BASF spol. sr. o., Praga, Czechy, 23 ss.

Boller E.F., Häni F., Poehling H.-M. 2004. Ecological Infrastructures. Ideabook on Functional Biodiversity at the Farm Level. Swiss Centre for Agricultural Extension and Rural Development (LBL), Eschikon, Switzerland, 212 pp.

Dąbrowski Z.T. 2010. Wzbogacenie oporu środowiska jako kierunek rozwoju metod biologicznych. [Enhancement of ecological resistance leading to the development of biological control]. Prog. Plant Prot./Post. Ochr. Roślin 50 (3): 1044-1052.

European Parliament. 2009. Directive 2009/128/EC of the European Parliament and of the Council of 21 October 2009 establishing a framework for Community action to achieve the sustainable use of pesticides. Official J. European Union 309/71, p. 34.

George D.R., Croft P., Northing P., Wäckers F.I. 2010. Perennial field margin with combined agronomical and ecological benefits for vegetable rotation schemes. IOBC/WPRS Bull. 56: 45-48.

George D.R., Croft P., Wakefield M., Wäckers F.I. 2012. Perrenial field margin for functional biodiversity in UK vegetable rotation schemes: Establishment and resources provision. IOBC/WPRS Bull. 75: 77-81.

Hurej M., Król J., Twardowski J. 1998. Attraction of aphid predators by cultivated and weedy strips. Aphids and other Homopterous Insects 6: 117-124.

Jervis M.A., Kidd N.A.C. 1986. Host-feeding strategies in hymenopteran parasitoids. Biol. Rev. 61: 395-434.

Nowacki J. (red.). 2007. Różnorodność biologiczna i jej ochrona. s. 9-23. W: „Zasoby przyrodnicze szansą zrównoważonego rozwoju”. Wydawnictwo AR im. A. Cieszkowskiego, 170 ss.

Perdikis D., Giatropoulos A., Labropoulos P., Maselou D., Fantinou A., Lykouressis D. 2007. The role of non-cultivated plants in the colonization of a tomato field by polyphagous mirid predatore. IOBC/WPRS Bull. 30 (8), p. 17.

Pfiffner L., Merkelbach L., Luka H. 2003. Do sown wildflower strips enhance the parasitism of lepidopteran pests in cabbage crops? IOBC/WPRS Bull. 26 (4): 111-116. 
Rossing W.A.H., Poehling H.-M., Burgio G. 2003. Landcape Management for Functional Biodiversity. IOBC/WPRS, Dijon, 220 pp. Ryszkowski L. 2002. Landscape Ecology in Agroecosystems Management. CRC Press, Boca Raton, London, New York, Washington, D.C., 366 pp.

Twardowski J. 2002. Wpływ zwiększonego zróżnicowania roślinnego w agrocenozach na populacje fitofagów i ich wrogów naturalnych. Rozprawa doktorska. Uniwersytet Przyrodniczy we Wrocławiu, 143 ss.

Twardowski J., Hurej M., Jaworska T. 2006. An effect of strip-management on carabid beatles (Col., Carabidae) in sugar beet crop. J. Plant Prot. Res. 46 (1): 61-71.

van Emden H.F., Dąbrowski Z.T. 1994. Biodiversity and habitat modification in pest management. Insect Sci. Applic. 15 (6): $605-620$.

van Helden M., Guenser J., Fulchin E. 2012. Evaluation of different ground covers to maintain botanical biodiversity in viticulture. IOBC/WPRS Bull. 75: 201-205.

Wäckers F.L., van Rijn P.C.J., Winkler K., Olson B. 2006. Flower power? Potential benefits and pitfalls of using (flowering) vegetation for conservation biological control. IOBC/WPRS Bull. 29 (6): 161-164.

Winkler K., Wäckers F., van Lenteren J. 2006. Strategic use of nectar sources to boost biological control. IOBC/WPRS Bull. 29 (6): $165-168$.

www.ecostac.uk 